
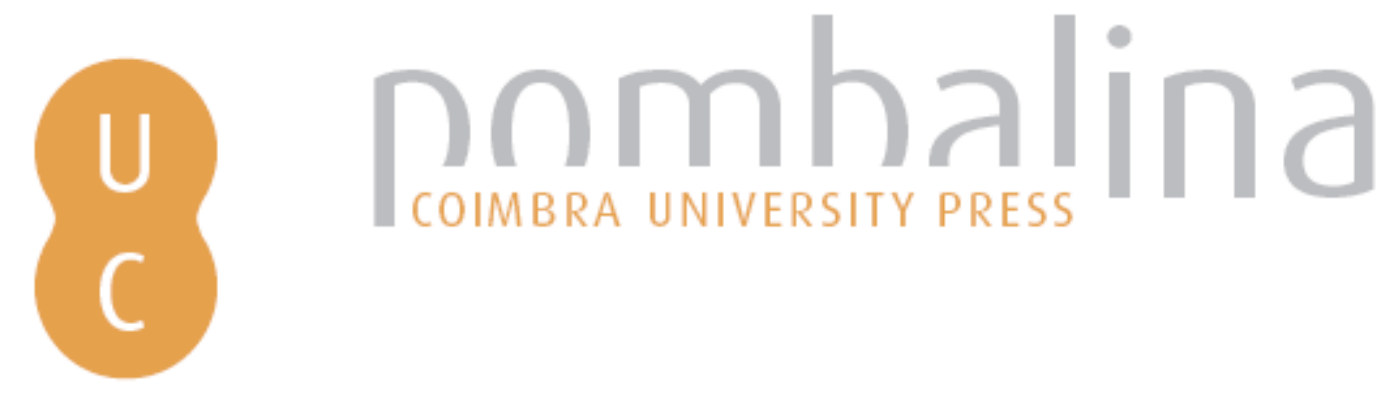

\title{
Gastronomia e vinhos: um produto sempre novo com raízes nas tradições da cultura da população portuguesa
}

\author{
Autor(es): $\quad$ Santos, Norberto \\ Publicado por: Imprensa da Universidade de Coimbra \\ URL \\ persistente: URI:http://hdl.handle.net/10316.2/43499 \\ DOI: DOI:https://doi.org/10.14195/978-989-26-1343-7_29 \\ Accessed : $\quad$ 26-Apr-2023 13:21:32
}

A navegação consulta e descarregamento dos títulos inseridos nas Bibliotecas Digitais UC Digitalis, UC Pombalina e UC Impactum, pressupõem a aceitação plena e sem reservas dos Termos e Condições de Uso destas Bibliotecas Digitais, disponíveis em https://digitalis.uc.pt/pt-pt/termos.

Conforme exposto nos referidos Termos e Condições de Uso, o descarregamento de títulos de acesso restrito requer uma licença válida de autorização devendo o utilizador aceder ao(s) documento(s) a partir de um endereço de IP da instituição detentora da supramencionada licença.

Ao utilizador é apenas permitido o descarregamento para uso pessoal, pelo que o emprego do(s) título(s) descarregado(s) para outro fim, designadamente comercial, carece de autorização do respetivo autor ou editor da obra.

Na medida em que todas as obras da UC Digitalis se encontram protegidas pelo Código do Direito de Autor e Direitos Conexos e demais legislação aplicável, toda a cópia, parcial ou total, deste documento, nos casos em que é legalmente admitida, deverá conter ou fazer-se acompanhar por este aviso.

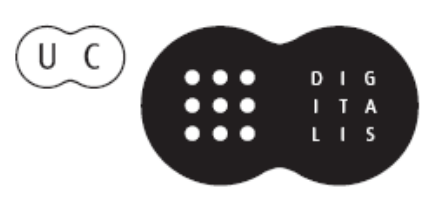




\section{FERNANDA CRAVIDÃO}

\section{IÚCIO CUNHA}

PAULA SANTANA

\section{NORBERTOSANTOS}

(ORG.)

\section{ESPAÇOS E TEMPOS EM GEOGRAFIA}

HOMENAGEM A ANTÓNIO GAMA

IMPRENISA DÁ UNIVERSIDADE DE COIMBRA COIMBRA UNIVERSITY PRESS

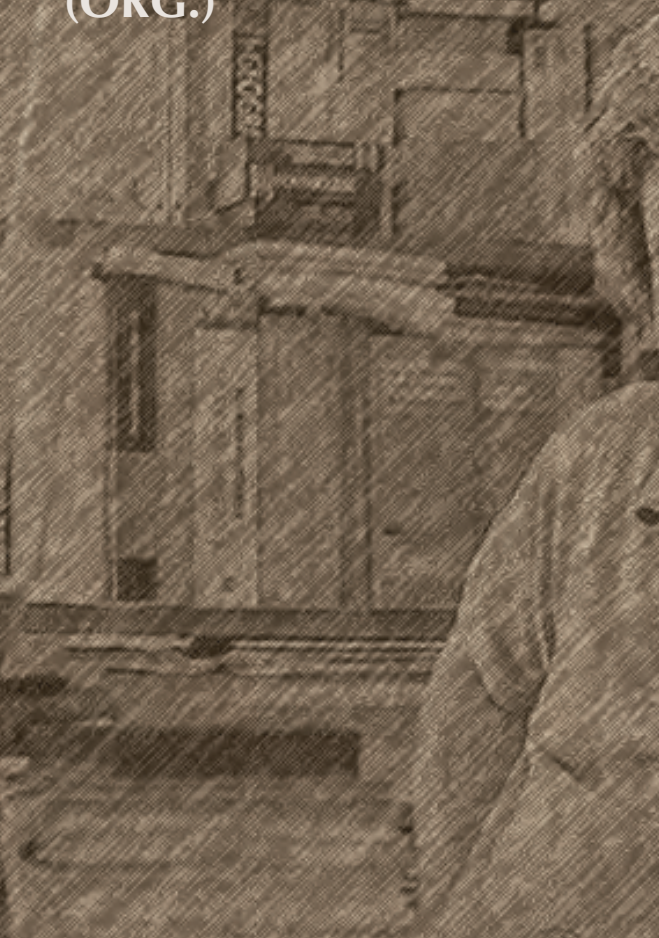




\title{
GASTRONOMIA E VINHOS ${ }^{I}$ UM PRODUTO SEMPRE NOVO COM RAÍZES NAS TRADIÇÓES DA CULTURA DA POPULAÇÁO PORTUGUESA
}

\author{
Norberto Santos/norgeo@ci.uc.pt \\ Centro de Estudos de Geografia e Ordenamento do Território \\ e Departamento de Geografia e Turismo \\ da Faculdade de Letras da Universidade de Coimbra
}

A nossa relação com o trabalho modificou-se significativamente ao longo das últimas décadas. Max Kaplan (Leisure in America: a social inquiry, 1960), Georges Hourdin (Une civilisations des loisirs, 1961), Nels Anderson (Work and Leisure: A Perceptive Inquiry Into Current Ways of Using Time, 1961), Joffre Dumazedier (Vers une civilisation du loisir? , 1962), entre muitos outros, perceberam cedo, no início da segunda metade do século xx, tal como Paul Lafargue (Le Droit à la paresse, 1880) e Thorstein Veblen (The Theory of the Leisure Class, 1899) o fizeram, muito antes do tempo de valorização do lazer como compensação para o tempo de trabalho, com a sua evocação da preguiça e da classe ociosa, respectivamente, que as relaçóes e valores sociais estavam em mutação, no sentido de uma civilização dos lazeres. Todavia, a interpretaçáo de uma sociedade sem trabalho tem uma longa história surgindo, por exemplo, associada ao modelo concebido por Deus para o trabalho e descanso humanos,

\footnotetext{
${ }^{1}$ A escolha deste tema decorre do facto de este ter sido o assunto científico que motivou o último trabalho conjunto com o saudoso amigo António Gama.
} 
recordado no Génesis, onde se afirma que Deus criou o universo em seis dias e descansou no sétimo (Veal, 2009).

A partir do entendimento de que seria possível atribuir um valor social ao tempo de lazer - mais ainda, um tempo de valor económico, porque produtivo a tempo inteiro (Sue, 1988) -, a organização dos tempos fora do trabalho ganhou um especial significado, até porque, até ao último quartel do século $\mathrm{xx}$, não havia uma estrutura da oferta capaz de motivar muitas das vontades e desejos que se encontravam esmagados pela pressão do valor social do trabalho.

A mudança, que adiante servirá de suporte a todo o discurso, permite novas formas de relação entre as pessoas, das pessoas com os bens e das pessoas com o seu espaço de vida, como nos foi referido por autores como John Kennett Galbraith (The affluent society, 1958), Pierre George (Géographie de la consommation, 1963), Claude Quin, Jean Boniface, Alain Goussel (Les consommateurs, 1965), Guy Débord (La société du spectácle, 1967), Jean Baudrillard (La société de consommation, 1970), Beja Santos, (O poder dos consumidores. Viver diferente, viver melhor, 1982), Gilles Lipovetsky (Ère du vide: essais sur l'individualisme contemporain, 1983), António Gama (Notas para uma Geografia do tempo livre, 1988), Michel Maffessoli (Le temps des tribus. Le déclin de l'individualisme dans les sociétés de masse, 1988), Restituto Zorrilla Castresana (El consumo del ocio, Una aproximación a la teoría del tiempo libre desde la perspectiva del consumo, 1990), Rob Shields (Lifestyle shopping. The subject of consumption, 1992), Zygmunt Bauman (Intimations of postmodernity, 1992) John Kennett Galbraith (The culture of contentment, 1992), George Ritzer (The Mcdonaldization of society, 1993), Robert Bocock (Consumption, 1993), Olivier Le Goff (L'invention du confort. Naissance d'une forme sociale, 1994), John Urry (Consuming places, 1995), Robert Rochefort (La société des consommateurs, 1995), Peter Jackson, Michael Rowlands, e Daniel Miller (Shopping, place and identity, 1998), Zygmunt Bauman (Liquid modernity, 2000), Norberto Santos (A sociedade de consumo e os espaços vividos pelas famílias, 2001), Gilles Lipovetsky e Sebastian Charles (Les temps hypermodernes, 2004), Luis Enrique Alonso (La era del consumo, 2005), Zygmunt Bauman (Liquid times: living in an age of uncertainty, 2006), 
Zygmunt Bauman (Consuming life, 2007), Gilles Lipovetsky (La culture-monde: réponse à une société désorientée, 2008).

A par com a promoção de processos de massificação turística, rapidamente se constituem outros modos mais identitários, autênticos, singulares, um novo turismo materializado em autores como Jost Krippendorf (The holiday makers. Understanding the impact of leisure and travel, 1987), Auliana Poon (Tourism, technology and competitive strategies, 1993), Marina Novelli (Niche tourism: contemporary issues, trends and cases, 2005); Greg Richards e Julie Wilson (From cultural tourism to creative tourism: the changing context of cultural tourism, 2008), José Manuel Simóes e Carlos Ferreira (Turismos de nicho: inovaçôes, produtos e territórios, 2009), Alexandre Panosso Netto e Cecília Gaetta (Turismo de experiência, 2010).

Estes turismos, capazes de promover a sustentabilidade e simultaneamente serem expressão de notoriedade e criadores de imagem, assumem-se como estimuladores de novas procuras. O turista e o visitante evidenciam modos muito diversificados de procuras, orientadas por motivaçóes cada vez mais diferenciadoras, quantas vezes agregadas na mesma pessoa, que afirmam propósitos diferentes em funçẫo das circunstâncias: o viajar sozinho, em família ou em grupo; a maior ou menor disponibilidade monetária; a existência de mais ou menos disponibilidade de tempo; os diferentes estados de espírito; o ambiente social do momento, entre outros.

Neste âmbito tem ganho importância o entendimento das razóes que levam, qualquer um de nós, a sentir necessidade de iniciar uma atividade de lazer ou uma viagem de turismo. O que se quer apresentar neste texto é a forma como os produtos de gastronomia e os produtos vínicos, referidos por um número crescente de investigadores, de que se salientam aqui alguns ${ }^{2}$ são por

\footnotetext{
2 Jukka Gronow (The sociology of taste, 1977), Jean-Robert Pitte (Gastronomie française. Histoire et géographie d'une passion, 1991) Michel de Certeau, Luce Giard e Pierre Mayol (L'invention du quotidien. 2. habiter, cuisiner, 1994), Claude Fischler (L'Homnivore, 2001) Jean-Pierre Poulain (Sociologies de l'alimentation, 2002), Regina Schluter (Turismo y património gastronómico. Una perspectiva, 2003), Regina Schluter (Gastronomia y turismo. Historias detrás de las recetas, 2004), Michael C. Hall (Wine, Food, and Tourism Marketing, 2004), Anne-Mette Hjalager, Greg Richards (Tourism and Gastronomy, 2004), Orlando Simóes (A vinha e o vinho no século XX, 2006), Michael
} 
nós interpretados como motivação, primária ou secundária, para qualificar a experiência individual ou de relação social.

\section{A gastronomia no turismo de Portugal}

Sabemos que a Gastronomia e Vinhos está a merecer uma atenção diferente daquela que foi proposta no Plano Estratégico Nacional de Turismo (PENT), de 2007, em que apenas algumas regióes do país teriam especial atenção, em termos de estratégia, por parte das entidades oficiais regionais e nacionais de turismo. Hoje, com o PENT 2013-2015 e com as linhas de orientação propostas pelo Turismo 2020, a Gastronomia e Vinhos é estrategicamente importante em todo o território nacional. Efetivamente, pode ler-se que importa "destacar o papel especial da Gastronomia e Vinhos na oferta turística nacional. Embora não se trate de uma motivação primária de viagem (ou seja, embora sejam poucos os turistas que viajam com o objetivo principal e quase único de disfrutar da gastronomia do destino), a gastronomia assume-se como um complemento essencial de todos os produtos turísticos. De facto, a gastronomia, bem como os vinhos portugueses, têm demonstrado uma enorme capacidade de agradar e surpreender quem nos visita. "Os inúmeros prémios internacionais e, acima de tudo, a opiniáo manifestada pelos turistas em sucessivos inquéritos de satisfação, confirmam a gastronomia e vinhos como um dos fatores mais fortes de valorização do destino Portugal” (Turismo 2020: 105).

C. Hall e Liz Sharples (Food and Wine Festivals and Events Around the World, 2008), Richards, Schiller, Montanari, Pite, Ascher, François (Le mangeur hypermoderne, 2005), Policarpo Lopes (A modernidade alimentar, In (E)volução simbólica do acto alimentar, 2006), Jonathan Nossiter (Mondovino. Gosto e poder no mundo do vinho, 2008), Ana Isabel Inácio (O Enoturismo em Portugal: da cultura da vinho ao vinho como cultura, 2008), Gilles Fumey e Olivier Etcheverria (Atlas mondial des cuisines gastronomiques, 2009), Anthony Rowley (Une histoire mondiale de la table. Stratégies de bouche, 2009), Massimo Montanari e Jean-Robert Pitte (Les frontières alimentares, 2009) Gilles Fumey (Manger local, manger global. L'alimentation géographique, 2010), Jean-Robert Pitte (La bouteille de vin. Histoire d'une révolution, 2013), Norberto Santos e Fernanda Cravidão (Gastronomia e vinhos, 2015). 
Já antes se via na valorizaçáo da gastronomia um modo de desenvolvimento local e promoçáo do lugar. Maria do Rosário Serafim, da Rede Portuguesa LEADER+/IDRHa, referia que a "riqueza, diversidade e qualidade da gastronomia portuguesa tem uma forte relaçáo com as identidades territoriais do nosso país, o que a torna num verdadeiro património cultural e social" (Serafim, 2005: 3). Efetivamente, a gastronomia e os vinhos são capazes de qualificar, de forma decisiva, qualquer destino turístico. Daí resultou a qualificação de produto estratégico complementar, quando a sua hierarquia náo se assume como primária.

Em 2007, o Relatório Anual de Pesquisa. Determinação da Representatividade das Motivaçôes Primárias e Estádio de Satisfação dos Turistas em Portugal, afirmava uma importância residual para a Gastronomia e Vinhos, mas delineava-se já uma evolução no sentido do crescimento e da qualidade deste produto turístico (Figura 1). Quando a motivação de visita estudada náo é a primária, verifica-se que $50 \%$ dos visitantes dão especial atenção aos Passeios Pedestres, às Experiências Gastronómicas e ao Património Monumental, sendo a motivação primária de City Break e Golfe que mais valoriza a oferta complementar de Gastronomia e Vinhos.

Assim, sabendo que a procura de experiência e de emoção é fulcral para um cada vez maior número de visitantes, o turismo gastronómico é um modo de valorização patrimonial local e deve configurar-se em torno da qualidade e da autenticidade do território. Aliás, sendo a autenticidade uma característica cada vez mais difícil de obter, a gastronomia, através da solicitação que efetua de todos os nossos sentidos, permite uma real vivência com a expressão cultural dos territórios. 


\begin{tabular}{l|l}
\hline \multicolumn{2}{c}{ Atividades de Lazer (\%) } \\
\hline Passeios Pedestres & 51,0 \\
\hline Experiências de Gastronomia & 50,9 \\
\hline Visita a Monumentos & 49,8 \\
\hline Visita a Parques Naturais & 39,6 \\
\hline Shopping (Compras) & 36,7 \\
\hline Diversão Noturna & 28,4 \\
\hline Feiras/Mercados Locais & 26,8 \\
\hline Viagem/Excursōes & 23,7 \\
\hline Passeios de Barco & 20,6 \\
\hline Wellness e SPA & 18,6 \\
\hline Ir a festas tradicionais & 14,8 \\
\hline Observação de Pássaros/Animais & 12,2 \\
\hline Visita ao Casino & 11,3 \\
\hline
\end{tabular}

\section{Figura 1}

Atividades executadas durante a visita. Actividades de lazer

Fonte: Adaptado de Determinação da representatividade das motivaçôes primárias e estádio de satisfação dos turistas em Portugal - RAP, 2007.

Neste âmbito ganha especial significado o estudo da satisfação do visitante e a possibilidade de superação das expectativas (Figura 2). O estudo efetuado pela Intercampus, em 2013, evidencia que os graus de satisfação dos turistas que visitam Portugal são elevados e muito elevados, especialmente no que diz respeito às Paisagens, às Praias e à Gastronomia e Vinhos (G\&V). Todavia, uma análise de maior pormenor permite verificar que o produto turístico G\&V consegue ultrapassar as expectativas em $46 \%$ dos casos, apenas ultrapassado 
pela superação conseguida pelas paisagens portuguesas (48\%). Quando a interpretação é efetuada com a separação entre Oferta Natural e Oferta Cultural, aí a $G \& V$ é, claramente, o produto de referência quanto ao reconhecimento e qualidade da oferta turística portuguesa.

\begin{tabular}{|c|c|c|}
\hline \multicolumn{3}{|c|}{ Grau de Satisfação (20|2) } \\
\hline \multicolumn{3}{|c|}{ Respostas 8,9 e 10 (escala de 0 a 10 ) } \\
\hline & & Superação de Expetativas \\
\hline Paisagens & $90 \%$ & $48 \%$ \\
\hline Praias & $88 \%$ & $45 \%$ \\
\hline Gastronomia e vinhos & $88 \%$ & $46 \%$ \\
\hline Simpatia da população Local & $87 \%$ & $42 \%$ \\
\hline Simpatia dos profissionais & $86 \%$ & $41 \%$ \\
\hline Profissionalismo dos profissionais & $85 \%$ & $39 \%$ \\
\hline Alojamento & $85 \%$ & $39 \%$ \\
\hline Monumentos/Museus & $82 \%$ & $38 \%$ \\
\hline Restaurantes & $81 \%$ & $37 \%$ \\
\hline Segurança & $79 \%$ & $38 \%$ \\
\hline Atividades náuticas & $78 \%$ & $32 \%$ \\
\hline Entretenimento & $77 \%$ & $34 \%$ \\
\hline Atividades de Natureza & $77 \%$ & $27 \%$ \\
\hline
\end{tabular}

Figura 2

Grau de satisfação e superação de expetativas

Fonte: Adaptado de Relatório de "Satisfação do turista". REST, 2013.

\section{O turismo gastronómico e vínico}

A importância da gastronomia está crescentemente presente na identidade dos territórios. Conforme se afirma na Carta Gastronómica do Alentejo. Monumenta Transtaganae Gastronomica "se o Alentejo tiver uma identidade, esta está na sua prática alimentar. Nesta identidade alimentar, que se estende do Rio Tejo às serras do Algarve, da fronteira com Espanha ao Atlântico, existem diferenças locais suportadas por uma mesma estrutura alimentar (...) um plano 
de salvaguarda para as práticas alimentares da Regiáo Histórica do Alentejo. E quando falamos de salvaguarda, falamos de reconhecimento, dignificaçáo, sustentabilidade e transmissão" (CGA, 2013, 88).

Os alimentos sempre tiveram, pelo seu carácter de necessidade básica, um valor social e económico mas, também um valor simbólico, com uma significação cultural, religiosa e mesmo política. Isso mesmo é expresso por Santos e Gama (2011) ao afirmarem que "a alimentação é um dos meios privilegiados para as sociedades efetuarem trocas de valores, relaçóes identitárias e prazeres. (...) A alimentação expressa uma diferenciação de civilizaçôes porque é pela comensalidade que surge a distinção entre o homem civilizado e os bárbaros: o primeiro junta ao alimento do corpo a valorizaçáo do espírito através da sociabilidade, algo que os segundos não fazem. (...) O terroir, muito apoiado no valor cultural resultante das relaçôes entre o económico, o político e o simbólico, ganha, pois, uma dinâmica própria em função da escala de ação, a local. Este, por sua vez, vinca uma relaçáo forte e tendencialmente irrepetível entre o produto e o lugar em que é produzido (...) Assim, um produto de terroir é aquele, como nos diz Brunet et al. (1993), que não poderia ser produzido noutro lugar que não naquele terroir" (Santos e Gama, 2011: 273-275).

Este valor, simultaneamente absoluto, concreto e simbólico, é motivador da viagem, devido às características de singularidade, de autenticidade, de identidade, mesmo de notoriedade e, reconhecidamente, hoje, de sustentabilidade, que oferece ao lugar e ao produto. Estas qualificaçôes quando aplicadas ao turismo remetem para o destino turístico e para o produto ou atração turística, tornando, quer como motivação primária, quer como motivação secundária, as manifestaçôes associadas aos alimentos locais, a forma de os confecionar, as harmonizaçóes, os restaurantes, as adegas, a paisagem que tudo integra, os festivais de vinhos e gastronomia, as oficinas gastronómicas, em elementos incontornáveis da oferta turística. Como refere Lucy Long (2010: 1) "comer é umas das minhas atividades favoritas quando viajo, e não estou sozinha nesta minha escolha”.

É com base nestas motivaçôes que o Turismo Gastronómico e Vínico ganha relevo e se assume como um elemento central da experiência de viagem e 
do carácter hedónico que lhe está associado. Esta perspetiva é especialmente valorizada por Krippendorf, 2001 (1ª edição em 1987); Poon, 1993; Martins, 2010; Marques, 2013; Moreira, 2014; Santos, 2014, entre outros) que valorizam um novo turismo, capaz de funcionar como alternativa ao turismo massificado, que deixou de conseguir responder a muitas das solicitaçóes dos novos turistas.

Este novo turista é significativamente diferente daquele cuja procura aconteceu durante as décadas de 60, 70 e 80 do século passado. De facto, "o turismo assume novos valores que se expressam, no final do século $\mathrm{xx}$, através das alterações socioeconómicas e culturais e de um novo modelo de participação sociopolítica. O turismo massificado passou a apresentar sinais de insuficiência da oferta porque deixa de dar resposta a um turista mais eclético para o qual a satisfação é atingida através da participação em práticas genuínas e experiências autênticas (MacCannell, 1976). O destino passa a ser visto como um local de aprendizagem e náo apenas local de descanso e fuga à rotina, o desenvolvimento e contacto com outras culturas são metas primordiais da viagem, tornando o turista num consumidor de edutenimento (entretendo-se aprendendo). Estes novos turistas são, como refere Poon (1993), (1) mais experientes, (2) mais envolvidos ambiental e eticamente, (3) mais flexíveis socio-espacialmente, (4) mais independentes e (5) associados a novas formas de relação sociofamiliar" (Santos, 2014: 70)

O produto turístico G\&V consegue, de facto, fazer "mexer" todos os sentidos da pessoa, promovendo uma das procuras primeiras dos turistas: a vivência emocional de experiências inusitadas ou diferenciadoras. Esta característica é de tal forma importante que passa a instigar, em todos aqueles que estáo na cadeia de valor, com especial relevância para os fornecedores (nomeadamente os da restauração), uma vontade de qualificação, contribuindo para a criação de iguarias associada à qualidade dos produtos que fornecem, de modo a serem degustados pelos visitantes/turistas, incrementando, assim, o desenvolvimento local. Estamos, então, perante um novo paradigma que encontra suporte no património cultural imaterial, na preferência pela experiência e participaçáo ativa, na assunçáo da sustentabilidade através da preservação da natureza que 
se constitui, hoje, simultaneamente, como um bem de consumo, associada à defesa do paradigma ecológico, inversamente relacionado com a resposta redutora conseguida pelo turismo de massas. O novo turista tem do destino o entendimento de um local de aprendizagem, de desenvolvimento e contacto com outras culturas, não apenas de local de descanso e fuga à rotina, mas de entretenimento e edutenimento, um consumidor que procura entreter-se aprendendo, de forma ativa e experiencial, envolvendo nos seus projetos de visita, tanto em formato soft como em formato hard, a emoção.

Mas o produto turístico de G\&V contribui também para desenvolvimento local e para a criação de emprego, ao mesmo tempo que contribui para a redução da sazonalidade, característica sempre presente na atividade turística, quer por motivos climáticos, quer sociais, profissionais ou, mesmo culturais. Este valor do turismo gastronómico surge associado, então, a esta nova forma de encarar as relaçóes com a viagem, com os lugares, com o consumo, com o lazer, simultaneamente entretenimento e desenvolvimento (Dumazedier, 1962). Por isso mesmo, o turista, hoje, quer mais do que apenas alguns dias para descansar: deseja que a sua vontade e expetativas sejam atendidas; interessa-se por viagens que o façam passar por sensaçóes ímpares; anseia por produtos e serviços diferenciados e diferenciadores; aspira a experiências emocionantes, que o conduzam a experiências sensoriais memoráveis (Netto e Gaeta, 2010).

A G\&V apresenta precisamente estas características. O turista gastronómico é, antes de mais, um turista que procura diferentes tipos de experiências que se sobrepóem com outros turistas com outros desejos e interesses, convencionais ou singulares. A gastronomia é um património cultural de eleição e a sua preservação é essencial para o reconhecimento das características dos lugares e das pessoas que os habitam.

Como seria de esperar, nem todas as pessoas têm o mesmo nível de interesse ou motivação relativamente ao produto turístico $G \& V$. No que diz respeito ao produto vinho Brown \& Getz (2005, citando Charters \& Ali-Knight, 2000) identificam os wine-lovers como aqueles que desejam ter experiências relacionadas com a produção de vinho e são visitantes com conhecimentos e interesses significativos sobre o mundo do vinho (Serrenho e Águas, 2006; Santos, 2008). 
Uma percentagem reduzida deste segmento é denominada connoisseur, aqueles que estấo mais interessados em saber tudo sobre o vinho, a sua produçáo e o saber-fazer com ele relacionado (Santos, 2008). Estes são os turistas que mais valorizam o produto vinho e que convivem com os os wine interested, visitantes com interesse elevado e conhecimentos reduzidos, e os wine curious, visitantes com interesse e conhecimentos reduzidos (Charters e Ali-Knight, 2000, citados por Serrenho e Águas, 2006). Os wine interested constituem o grupo predominante composto essencialmente por mulheres entre os 27 e os 48 anos com elevado nível educacional e rendimento salarial. Na última posição estão os wine curious. Em Portugal, o Turismo de Portugal (2006) define o perfil do turista de G\&V como sendo homem, isolado, com entre 35 e 60 anos, com elevado poder de compra e com habilitaçôes literárias e elevadas. Procura hotéis de 3 a 5 estrelas ou turismo rural, sem influência da sazonalidade, ficando no território da visita de 3 a 7 dias. Serrenho e Águas (2006) referem que os turistas de G\&V procuram: conhecer a história da marca e o design da etiqueta do vinho; provar e comprar vinho; conhecer o produtor; valorizar as outras atraçóes culturais do território; residem predominantemente em regióes urbanas; apreciam o vinho excecional; são de meia-idade e elevado nível salarial e educacional; a mulher está cada vez mais presente.

\section{Da globalização à identidade}

A relação da população com o consumo de alimentos tem sofrido uma evolução significativa. O final do século XIX foi marcante, devido às mudanças que ocorreram na cidade, resultado de uma revoluçáo industrial que começou a atrair para as cidades uma parte significativa da população, da envolvência próxima e de paragens mais distantes. Concomitantemente estes processos de urbanização e industrialização foram responsáveis pelo início da pressão sobre o tempo, com o valor social do trabalho a ditar as regras comportamentais dos urbanitas. Assim, não é de estranhar que nas sociedades onde a revolução industrial teve mais impacto se possam ver interpretaçôes da relação das pessoas com 
os períodos de refeição como aquela que Flandrin e Montanari (1996) abaixo descrevem: "Os americanos mostram ter um apetite feroz; insistem em comer o mais depressa possível, em especial os businessmen de Chicago ou de NY. Nestas duas cidades existem desde o início do século xx self-services que servem refeiçóes aos colarinhos brancos. Que as pedem ao balcão e as consomem à mesa, tudo a um ritmo tão rápido que são conhecidos por smash-and-grab places. Paul Rousiers (1892) descreve: É a hora do almoço. As ruas enchem-se de novo. Em NY ninguém vai a casa a meio do dia: comem no local, quer nos escritórios, enquanto trabalham, quer nos clubes, quer nas cafetarias. Nas casas de pasto populares, milhares de seres de chapéu na cabeça, alinhados numa única fila como num estábulo, devoram alimentos, sem dúvida frescos e apetitosos, por preços inferiores aos nossos. Atacam pratos cheios de almôndegas; atrás deles, outros esperam pelos seus lugares" (Fischler, 1996: 422).

Efetivamente, a pressão sobre o tempo da passagem do século xix para o século xx vai manter-se e aumentar até à atualidade. A oferta de restauração vai inovando criando propostas para procuras crescentemente massificadas, para ir ao encontro também da redução das despesas, devido ao facto de parte significativa das refeiçôes familiares ter saído do lar e passado para o mercado, acessível nos mais diversos espaços públicos e privados. Flandrin e Montanari (1996) permitem identificar alguns momentos cruciais desta evolução de que se salientam: a abertura do $1 .^{\circ}$ drive-in, por Dick e Mac McDonald, em 1937, em Pasadena, resultante da importância que o automóvel passou a ter na vida de todo aqueles que usam com muita frequência ou pendularmente, o espaço urbano. Ao mesmo tempo, criam, em San Bernardino, devido à presença de grande número de jovens, um restaurante de venda de cachorros quentes, em 1940. Esta proposta veio a promover o processo de afastamento dos teenagers das suas famílias, ao criar uma enorme segmentação, em termos de desejos, por parte dos diferentes membros da família. O fordismo e a produção massificada, associada à imagem da linha de montagem, valorizada por Ritzer (1993) que a define como McDonaldização, faz aparecer, em 1948, um novo restaurante de hambúrgueres, sem pratos e sem talheres, utilizando sacos de papel, com um preço extraordinariamente baixo, 15 cêntimos, captando uma clientela em 
crescimento, as famílias operárias, sem, todavia, não esquecer a importância da limpeza e da higiene, através da utilização da cor branca e do aço inoxidável. É o taylorismo, produção em cadeia e em série com encomendas em poucos segundos, que chega à oferta de produtos alimentares confecionados, acompanhado pelos processos de imitação e franchising que diversificam as marcas e integram uma multiplicidade de produtos ancorados na McDonald's e seguida, em 1950, pela Kentucky Fried Chicken e depois pelos produtos étnicos, como os Taco Bell, e pelos produtos identitários, a partir daí massificados, como a Pizza Hut, no final da década de 1950. O fast-food, associado à imagem de grandes centros comerciais de restauração, vai invadir os produtos alimentares identitários e étnicos e a partir das décadas de setenta e oitenta, do século Xx, Itália com as pizzas, Espanha com as tortilhas, México com os tacos, China com chop suey, Japão com o sushi, Grécia com pittas e falafels, França com os croissants, surgem em qualquer parte do mundo.

Hoje, temos, de facto uma conjugação específica entre a globalização e a promoção do local. Um dos elementos que melhor expressa este ponto de vista, em termos de G\&V são as Listas Representativas do Património Cultural Imaterial da Unesco que ao passarem a integrar desde 2009, no caso das cidades criativas da Gastronomia, 2010, no caso dos produtos alimentares e gastronómicos locais e, antes disso, de elementos territoriais inscritos na Lista de Património Mundial da Unesco (Outstanding Universal Value $)^{3}$. Esta relação forte entre o local e o global, diretamente associados ao produto G\&V, encontra-se bem expressa por Mak et al. (2012) ao referir-se à influência da globalização na oferta gastronómica e consumo de alimentos no turismo.

\footnotetext{
${ }^{3}$ Alto Douro Wine Region (Portugal), Champagne Hillsides, Houses and Cellars (França), Climats, terroirs of Burgundy (França), Coffee Cultural Landscape of Colombia (Colômbia), Cultural Landscape of Honghe Hani Rice Terraces (China), Landscape of the Pico Island Vineyard Culture (Portugal), Jurisdiction of Saint-Emilion (França), Lavaux, Vineyard Terraces (Suíça), Palestine: Land of Olives and Vines - Cultural Landscape of Southern Jerusalem, Battir (Palestina), Rice Terraces of the Philippine Cordilleras (Filipinas), Tokaj Wine Region Historic Cultural Landscape (Hungria), Traditional agricultural practice of cultivating the 'vite ad alberello' (head-trained bush vines) of the community of Pantelleria (Itália), Vineyard Landscape of Piedmont: Langhe-Roero and Monferrato (Itália).
} 
A necessidade de uma oferta estandardizada associada a tempos curtos, à pressão sobre o tempo, a preços cómodos, a proximidade com o local de emprego e a acessibilidade e mobilidade elevadas, são proposiçóes das ofertas de fast-food que se encontram difundidas em todo o mundo e gozam de uma comunicaçáo, divulgação e publicitação ecuménica. Como referem Mak et al. (2912) esta oferta é coincidente com a homogeneização e com uma cultura global, normalmente articulada com situaçóes de obrigatoriedade, familiaridade e com rotinas quotidianas. Por outro lado, a importância que hoje damos ao simbólico, à novidade e à diferenciação promove a procura da cultura local que encontra uma expressão superlativa na G\&V e permite a fuga aos processos rotineiros. Isto porque a cozinha é "uma linguagem na qual cada sociedade codifica as mensagens que lhe permitem significar ao menos uma parte do que essa sociedade é" (Lévi-Strauss, 1968). Mais do que isso, o regime alimentar é o ponto central do espaço social e do qual comanda a tecnologia e a economia de grupo (Condominas, 1980).

Mak et al. (2012, 175) referem, citando Hannerz (1992) "que, embora muitas culturas se estejam a tornar cada vez mais subculturas dentro da cultura global, estas subculturas ainda podem manter um certo grau de diferenciaçáo, o que implica uma diferenciação conceitual de cultura global e cultura local. Ele afirma que as relações entre o núcleo e a periferia envolvem a difusão, bem como a diferenciaçáo e uma nova cultura pode ser gerada na periferia através do uso criativo de recursos importados ou de recursos locais..."

Esta é uma interpretação coincidente com a que efetua Clarke (2010) ao valorizar a posição de convergência das proposiçóes de sustentabilidade em turismo, assumindo que se trata de um objetivo de todo o mercado turístico, independentemente da escala. É por isso que o turismo associado a grandes empresas promove técnicas para induzir mudanças no comportamento turístico compatível com a viagem ambientalmente amigável e com o componente educacional estimulado pelas empresas de pequena escala. Por seu lado, as pequenas empresas integram elementos de desenvolvimento de sistemas de gestáo ambiental eficazes, originalmente território de grandes organizaçóes de turismo. Os processos de globalização, materializados no turismo associado a grandes 
empresas, refletem-se na interpretação das pequenas empresas, de âmbito local, sobre o turismo sustentável que passam a dar especial atenção 1) a orientaçôes e códigos de boas práticas, 2) à definição de projetos baseados no destino, 3) à oferta de consultoria e divulgação às partes interessadas.

\section{Considerações finais}

Em termos de $\mathrm{G} \& \mathrm{~V}$ assume-se aqui a influência biunívoca especialmente motivada pela acessibilidade e divulgação informativas tendencialmente integrais e pela necessidade de, perante essa omni-informação, se fomentar através dos elementos mais carismáticos e facilmente veiculados da cultura local, a Gastronomia e Vinhos, a identidade, a autenticidade, a singularidade, a no-

toriedade e a sustentabilidade. É por isso que, como refere Inácio (2009), o enoturismo, enquanto modo particular do turismo gastronómico é um importante elemento do Turismo cultural. Isto é fundamentado no facto de este turismo se basear na valorização de tradições ancestrais, ao mesmo tempo que integra traços de inovação e modernização no que diz respeito à quantidade de pessoas envolvidas, à dinamização da agricultura e a motivaçóes específicas relacionadas com o terroir. Esta expressáo territorial da G\&V ganha especial expressão nesta temática porque, como refere Tonietto (2007) o terroir conecta-se com a origem, a diferenciação e a originalidade dos produtos, escapando à uniformização, à padronização e à estandardização. São as tradiçóes gastronómicas locais que se assumem como marcas territoriais e elementos de experienciação e participaçáo capazes de integrar os visitantes na cultura local e obterem formas criativas de turismo. Como afirmam Flandrin e Montanari (1996), a "redescoberta" da cozinha de aldeia e das tradiçóes gastronómicas locais acompanhou a negação dos seus direitos pela indústria alimentar. Atualmente, as cozinhas regionais fazem parte do património comum, facto de que estamos sem dúvida mais conscientes do que no passado. Atualmente, a cozinha da aldeia e o carácter sazonal dos alimentos tornaram-se valores objetivos primordiais e prestigiosos. É por isso que as práticas de G\&V devem ser vistas como o enaltecimento da 
diferença e a salvaguarda da identidade local e, simultaneamente, como um caminho de futuro para promover o desenvolvimento local, através de práticas inovadores e diferenciadoras mas assumidamente assentes na autenticidade, no storytelling de processos, relaçóes e saber-fazer e no marketing experiencial, superador das mais exigentes expectativas.

\section{Bibliografia}

Anderson, Nels (1961). Work and Leisure: A Perceptive Inquiry Into Current Ways of Using Time. London: Routledge.

Ascher, François (2005). Le mangeur hypermoderne. Une figure de l'individu écléctique, Paris, Odile Jacob.

Athena H.N. Mak, Margaret Lumbers, Anita Eves - Globalisation and food consumption in tourism. Annals of Tourism Research, Volume 39, Issue 1, January 2012, pp. 171-196.

Baudrillard, Jean (1970). La société de consummation. Paris: Denoël.

Bauman, Zygmunt (1992). Intimations of Postmodernity. Cambridge: Polity.

Bauman, Zygmunt (2000), Liquid Modernity. Cambridge: Polity.

Bauman, Zygmunt (2006). Liquid Times: Living in an Age of Uncertainty. Cambridge: Polity.

Bauman, Zygmunt (2007). Consuming Life. Cambridge: Polity.

Bocock, Robert (1993). Consumption, Key Ideas. London: Routledge.

Carta Gastronómica do Alentejo. Monumenta Transtaganae Gastronomica (2013). Entidade Regional de Turismo do Alentejo. Évora.

Condominas, Georges (1980). L'Espace social. À propos de l'Asie du Sud-Est, Paris: Flammarion.

De Certeau, Michel; Giard, Luce; Mayol, Pierre (1994). Linvention du quotidien. 2. habiter, cuisine. Collection Folio Essais, Pais: Gallimard.

Débord, Guy (1967), La société du spéctacle. Paris: Buchet/Chastel.

Enrique Alonso, Luis (2005). La era del consumo, Madrid: Siglo XXI.

Fischler, Claude (1996). A Mcdonaldização dos costumes. In Flaudrin, Jean-Loius; Montanari, Massimo, Histoire de L'Alimentation, 2, Paris: Fayard, pp. 412-430.

Fischler, Claude (2001). L'Homnivore. Paris: Odile Jacob.

Flandrin, Jean-Louis; Montanari, Massimo (1996). Histoire de L'Alimentation, Paris: Fayard.

Fumey, Gilles (2010). Manger local, manger global. L'alimentation géographique. Paris: CNRS-Editions.

Fumey, Gilles; Etcheverria, Olivier (2009). Atlas mondial des cuisines gastronomiques. Paris: Autrement.

Galbraith, John Kennett (1958). The Affluent Society. Boston: Houghton Mifflin Harcourt.

Galbraith, John Kennett (1992). The Culture of Contentment. Boston: Houghton Mifflin Company. 
Gama, António (1988), Notas para uma Geografia do tempo livre, Cadernos de Geografia, 7 , pp. 203-217.

George, Pierre (1963). Géographie de la consummation. Paris: PUF.

Gilles Lipovetsky 1983). L'Ėre du vide: essais sur l'individualisme contemporain. Paris: Gallimard.

Gronow, Jukka (1977). The sociology of taste, London: Routledge.

Hall, Michael C. (2003). Wine, Food, and Tourism Marketing. New York: Haworth Hospitality Press.

Hall, Michael C. \& Sharples, Liz (2008). Food and Wine Festivals and Events Around the World. Oxford: Elsevier.

Hjalager, Anne-Mette \& Richards, Greg (2004). Tourism and Gastronomy. London: Routledge.

Inácio, Ana Isabel (2008). O Enoturismo em Portugal: da cultura da vinha ao vinho como cultura. Tese de doutoramento, Geografia (Planeamento Regional e Urbano), 2009, Universidade de Lisboa, Faculdade de Letras.

Jackie Clarke (1997) A Framework of Approaches to Sustainable Tourism, Journal of Sustainable Tourism, 5(3), pp. 224-233.

Jackson, Peter; Rowlands, Michael; Miller, Daniel (1998). Shopping, place and identity. Londres: Routledge.

Kaplan, Max (1960). Leisure in America: a social inquiry. New York: Wiley.

Krippendorf, Yost (2001). The Holiday Makers. Understanding the impact of leisure and travel. Oxford: Butterworth-Keinemann.

Lafargue, Paul (1991). O direito à preguiça. Lisboa: Editorial Teorema (1. a edição, 1880).

Le Goff, Olivier (1994). L'invention du confort. Naissance d'une forme sociale, Lyon: Présses Universitaires de Lyon.

Lévi-Strauss, Claude (1968). L'origine des manières de table, Mythologies. Paris: Librairie Plon.

Lipovetsky, Gilles (2008). La culture-monde: réponse à une société désorientée. Paris: Odile Jacob.

Lipovetsky, Gilles \& Charles, Sebastian (2004). Les temps hypermodernes. Paris: Grasset.

Long, Lucy M. (ed.) (2010). Culinary tourism. Kentucky: The University Press of Kentucky.

Lopes, Policarpo (2006). A modernidade alimentar. In (E)voluçâo simbólica do acto alimentar. Lisboa: Colibri.

Maffessoli, Michel (1988). Le temps des tribus. Le déclin de l'individualisme dans les sociétés de masse. Paris: Méridiens Klincksieck.

Mak, Athena H. N.; Lumbers, Margaret; Eves, Anita (2012) Globalisation and food consumption in tourism, Annals of Tourism Research, 39, Isue 1, January, pp. 171-196.

Montanari, Massimo \& Pitte, Jean-Robert (2009). Les frontières alimentares. Paris: CNRS-Editions.

Netto, Alexandre Panosso \& Gaetta, Cecília (2010). Turismo de experiência. São Paulo: Senac.

Nossiter, Jonathan (2008). Mondovino. Gosto e poder no mundo do vinho. Lisboa: Sextante.

Novelli, Marina (2005). Niche tourism: contemporary issues, trends and cases. London: Routledge.

Pitte, Jean-Robert (1991). Gastronomie française. Histoire et géographie d'une passion. Paris: Fayard.

Pitte, Jean-Robert (2013). La Bouteille de vin. Histoire d'une révolution. Paris: Tallandier. 
Poon, Auliana (1993). Tourism, technology and competitive strategies. Wallingford: Oxfordshire: CABI.

Poulain, Jean-Pierre (2002). Sociologies de l'alimentation. Les mangeurs et l'espace social alimentaire. Paris: PUF.

Quin, Claude; Boniface, Jean \& Goussel, Alain (1965). Les consommateurs. Paris: Editions Seuil.

RAP, 2007. Relatório Anual de Pesquisa. Determinação da Representatividade das Motivaçóes Primárias e Estádio de Satisfação dos Turistas em Portugal. IMR - Instituto de Marketing Research. Lisboa: Turismo de Portugal.

REST, 2013. Relatório de "Satisfação do Turista". Estudo Satisfação de Turistas. Análise de Resultados, Intercampus. Lisboa, Turismo de Portugal.

Richards, Greg \& Wilson, Julie (2008). From Cultural Tourism to Creative Tourism: The changing context of cultural tourism. Arnhem: ATLAS.

Ritzer, George (1993). The Mcdonaldization of society. Pine Forge Press, Sage, Newbury Park.

Rochefort, Robert (1995). La société des consommateurs, Paris: Odile Jacob.

Rowley, Anthony (2009). Une histoire mondiale de la table. Stratégies de bouche. Paris: Édile Jacob.

Santos, Beja (1982). O poder dos consumidores. Viver diferente, viver melhor. Lisboa: A Regra do Jogo.

Santos, Norberto (2001). A sociedade de consumo e os espaços vividos pelas famílias. A dualidade dos espaços, a turbulência dos percursos e a identidade social. Lisboa: Colibri, CEGOT.

Santos, Norberto (2014). Turismo, gestão e território. Caderno Virtual de Turismo. Ediçáo especial: Hospitalidade e políticas públicas em turismo. Rio de Janeiro, v. 14, supl.1, pp. 66-86.

Santos, Norberto \& Cravidáo, Fernanda (2015). Gastronomia e Vinhos. Do turismo de experiência à experiência pelo turismo. Coimbra: Minerva, CEGOT.

Santos, Norberto \& Gama, António (2011). As tradições do pão, territórios e desenvolvimento. In Santos, Norberto \& Cunha, Lúcio (orgs.), Trunfos de uma Geografia Ativa. Coimbra: CCDRC, IUC.

Schluter, Regina (2003). Turismo y património gastronómico. Una perspectiva. Buenos Aires: Centro de Investigationes y Estudíos Turisticos.

Schluter, Regina (2004). Gastronomia y turismo. Historias detrás de las recetas. Buenos Aires: Centro de Investigationes y Estudíos Turisticos.

Serafim, Maria do Rosário (2005). Territórios, gastronomia e diversidade cultural. Pessoas e Lugares, 26, II série: 3 .

Serrenho; Marisa \& Águas, Paulo (2006). Perfil do enoturista, Revista da ESGHT-Algarve, pp. 21-30.

Shields, Rob (ed.) (1992). Lifestyle shopping. The subject of consumption. The international library of sociology. Routledge: Londres.

Simôes, José Manuel \& Ferreira, Carlos (2009). Turismos de Nicho: inovaçöes, produtos e territórios. Lisboa: Centro de Estudos Geográficos

Simôes, Orlando (2006). A vinha e o vinho no século XX. Crises e regulação. Oeiras, Celta Editora. 
Turismo 2020 (sd). Cinco princípios para uma ambição. Tornar Portugal o destino turístico mais ágil e dinâmico da Europa (Documento para Consulta Pública). Turismo de Portugal, Lisboa. Ministério da Economia,

Urry, John (1995). Consuming places. The International Library of Sociology. Routledge: Londres.

Veal, A. J. (2009). The elusive leisure society, Fourth Edition, July, Working Paper 9, School of Leisure, Sport and Tourism.

Veblen, Thorstein (1899). The theory of the leisure class. A teoria da classe ociosa. Um estudo económico das instituiçóes. São Paulo: Livraria Pioneira Editora.

Williamson, Judith (1991). Consuming passions. The dynamics of popular culture. London: Marion Boyars.

Zorrilla Castresana, R. (1990). El consumo del ocio, Una aproximación a la teoría del tiempo libre desde la perspectiva del consumo. Departamento de sanidad y consumo, Direccion de Consumo. 